\title{
Understanding factors of ambulance delay and crash to enhance ambulance efficiency: An integrative literature review
}

\author{
Ketut Shri Satya Wiwekananda, ${ }^{1, *}$ Rizqiko Pandai Hamukti, ${ }^{1}$ Ketut Shri Satya Yogananda, ${ }^{1}$ Kadek \\ Egadia Calisto, ${ }^{1}$ and Prattama Santoso Utomo ${ }^{2}$
}

${ }^{1}$ Department of Medicine, Faculty of Medicine, Public Health, and Nursing Universitas Gadjah Mada, Yogyakarta, Indonesia

${ }^{2}$ Department of Medical Education and Bioethics, Faculty of Medicine, Public Health, and Nursing Universitas Gadjah Mada, Yogyakarta, Indonesia

KEYWORDS

Ambulance crash

Ambulance delay

Ambulance efficiency

Prehospital care
ABSTRACT Trauma is one of the major causes of deaths worldwide. The referral time of trauma patients to the trauma center is a vital determinant of traumatic injury patients' survival. Ambulance delays and crashes are the major causes of delay of patient transportation to the hospital. This review was conducted to find the main factors that cause ambulance crashes and ambulance delays; and discuss the correlation of both factors. Hence, the authors might suggest an appropriate solution to minimize ambulance delay and crash incidents. This integrative literature review applied the PRISMA-P protocol to ensure a robust literature search. A total of nine databases and publishers (i.e., PubMed, Scopus, ScienceDirect, ASCE Library, Clinical Key, EBSCO, Cambridge, Taylor \& Francis, and ProQuest) were searched using relevant keywords to obtain studies on ambulance delays and ambulance crashes. The literature search retrieved 620 studies to be screened based on the exclusion-inclusion criteria which finally resulted in the 12 studies included in the review. The researchers conducted a risk of bias assessment using Joanna Briggs Institute's critical appraisal tools. Data from the included studies were then extracted and analyzed using descriptive statistics to identify the factors affecting ambulance delays and crashes. After conducting an integrative literature review, the main factor that causes ambulance delays is traffic congestion. Meanwhile, the main factor causing ambulance crashes is intersection. Traffic congestion often occurs especially at intersections. The authors concluded that, intersections have a significant effect on ambulance delays and also ambulance crashes. To overcome this problem, the authors suggest to make an additional ambulance caution signal lamp on all congested intersections.

(c) The Journal 2020. This article is distributed under a Creative Commons Attribution-ShareAlike 4.0 International license.

\section{Introduction}

Trauma contributes a significant number of deaths worldwide. The global data in 2014 reported that, trauma caused more than 5 million deaths worldwide and had a prevalence of $9 \%$ of the total world's deaths, totaling nearly 1.7 times the number of deaths caused by HIV/AIDS, tuberculosis, and malaria combined. ${ }^{1}$ In the United States, trauma was the number one cause of death in people with age range between 1-44 years old in 2017.2 Approximately $90 \%$ of global injury-related deaths occur in low-

\footnotetext{
*Correspondence: ketutshri01@mail.ugm.ac.id

Faculty of Medicine, Public Health and Nursing Universitas Gadjah Mada, Jl. Farmako, Sekip utara, Sleman Yogyakarta, Indonesia
}

and middle-income countries, which becomes a challenge for developing countries, possessing a lack of trauma care resources. ${ }^{3}$ Statistics for Road Traffic Injuries (RTIs) also show that an estimated $90 \%$ of RTIs occur in low and middle-income countries. ${ }^{4}$ Even in Indonesia every 3 hours, there are deaths due to traffic accidents. ${ }^{5}$

Trauma patients require immediate medical treatment to improve survival and prevent disabilities. $^{3}$ Pre-hospital Emergency Medical Services (EMS) is the first level of treatment provided to patients suffering from life-threatening conditions by emergency medical technicians (EMT) and paramedics before being submitted to the hospital in many countries. EMS seek to reduce response time because the longer time for patients to get medical 
treatment is correlated with the higher number of deaths occurring out of the hospital. Response time is the time between when an emergency call is made to the ambulance station and the time an ambulance arrives at the scene for assistance.

However, ambulance delay becomes a major obstacle for patients to receive immediate EMS assistance. Ambulance delays may worsen the patient's injury. More than $20 \%$ of patients needing emergency treatment have died on their way to the hospital because of delays due to traffic jams and uncooperative motorists. ${ }^{6}$ Moreover, there are many cases of traffic accidents that involve ambulances. The National Highway Traffic Safety Administration (NHTSA) shows there are an estimated 4,500 ambulance crashes per year with $37 \%$ of them resulting in injuries. ${ }^{7}$

Ambulance delays and ambulance crashes are threats that should be taken seriously to improve patients' survival during trips to the hospital. Factors causing these threats must be clarified to facilitate actions that can be taken to overcome the problem. Therefore, the authors conducted an integrative literature review to better understand the main factors causing ambulance crashes and ambulance delays; and discuss the correlation of both factors. Hence, a solution to minimize ambulance crash and delays might be suggested.

\section{Method}

\subsection{Data Collection Technique}

\subsubsection{Search Strategy}

The integrative literature review was conducted on nine databases, e.g., PubMed, Scopus, ScienceDirect, ASCE Library, Clinical Key, EBSCO, Cambridge, Taylor \& Francis, and ProQuest. A set of keywords were used to find articles that discuss factors that cause ambulance delays, for instance: (factor OR cause) AND ("ambulance response time" OR "ambulance delay" OR "emergency response time" OR "pre-hospital response time"). The keywords used to find articles that discuss factors causing ambulance crashes were: (factor OR cause OR characteristic) AND ("ambulance crashes" OR "ambulance accidents" OR "emergency medical vehicle collisions").

\subsubsection{Study Selection}

The included studies fulfilled several inclusion criteria. They should discuss the factors that cause ambulance delay and ambulance crashes; written in English; using cross-sectional methods, cohort studies, and qualitative studies; and published no later than 20 years ago. The authors applied a considerable time limit due to the limited articles on this topic. The study would be excluded if the full text of the study was inaccessible; discussed about air ambulance or water ambulance, only focused on single factor and focused on discussing prehospital treatment in patients.

\subsubsection{Risk of Bias Assessment}

This review assigned two reviewers to evaluate all included studies independently. This method was considered as reviewer triangulation, to avoid reviewer bias. ${ }^{8}$ Both reviewers also evaluated the journals using a critical appraisal checklist from the Joanna Briggs Institute's Critical Assessment Tools, ${ }^{9}$ a source of validated quality appraisal tools. Finally, articles that obtained high validity score were processed for data extraction and synthesis.

\subsection{Data Analysis}

Data from included studies were then extracted. To obtain data such the place where the research was conducted, the date of the study was collected with the method, the number of research subjects involved, and the results of the research. Subsequently, the obtained data were analyzed using descriptive statistical methods. To summarize the results of each journal, the authors extracted the three most important factors about ambulance delays and ambulance crashes based on the obtained study. Then, the authors combined the three most preferred factors from each article and they were interpreted in graphical form. Ultimately, the authors decided on the most important factors of ambulance delays and ambulance crashes from the included articles.

\subsection{Literature Search Timeframe}

The literature search was conducted from February to March 2020. 


\section{Result}

\subsection{Risk of bias assessment}

Systematic assessments of biases in the included studies were done using Joanna Briggs Institute's critical assessment tools to ensure their validity. A total of twelve studies consisting of three types of research methods, namely cohort, qualitative, and cross-sectional with 7, 3, and 2 studies, respectively. The assessment of each study was done using appropriate appraisal tools for each research method. The results of the study assessment show that all studies included were considered as high quality. Tables 1, 2 and 3 show appraisal results on studies using Joanna Briggs Institute's Critical Assessment Tools.

\subsection{Study Search Results}

The literature search and selection process are illustrated in Figure 1 . We retrieved 620 articles from 9 databases and other sources (manual search and bibliography from another study). Full-text of 12 articles were assessed for eligibility after the exclusion of duplicated 25 studies. A total of 576 studies were excluded due to several reasons, for instance, studies published before $2000(n=208)$, inappropriate study design $(n=116)$, did not correlate to the topic $(n=247)$, or were not fully accessible $(n=3)$. Ultimately, 12 studies were included to be extracted and synthesized in this integrated review.

\subsection{Factor of Ambulance Delay}

\subsubsection{Study Characteristics}

Seven studies which were obtained were then accessed in full text. Out of the 7 studies that have been accessed, 4 studies were conducted in developed countries, and 3 studies were conducted in developing countries. All studies discussed the factors that cause ambulance delay, with 2 studies using qualitative methods to determine the factors that cause ambulance delay, 2 studies using cohort studies to look for factors that cause ambulance delay, and 3 studies using cross sectional research for causal factors related to ambulance delay. There were 123 respondents for the qualitative study, 49,798 patients in the cohort studies, and 149 patients in the cross-sectional study.

\subsubsection{Outcomes}

In the study conducted by Patel and his friends, ${ }^{4}$ traffic conditions are the main cause of ambulance delays, followed by bad location and lack of personnel. In a study conducted by Noorani, ${ }^{10}$ what influenced ambulance delay are traffic conditions, transportation availability, and distance of travel. In another study, Dimitriou, Efthymiou and Antoniou ${ }^{11}$ also stated that traffic jams and congestion in urban areas and the lack of cooperation of people with EMS ambulances are factors that affect ambulance delays. The study conducted by Lam and his friends ${ }^{12}$ stated that traffic conditions had the most significant influence on ambulance response time followed by weather and scene. The study conducted by Griffin and $\mathrm{McGwin},{ }^{13}$ also supports that traffic conditions are the main cause of ambulance delay. In another study conducted by Xue and Weng, ${ }^{14}$ the most influencing factor for ambulance delay was holidays followed by bad weather and poor light conditions. The study conducted by Saleh et al., ${ }^{15}$ also provided different factors causing ambulance delay, namely knowledge of local ambulance phone number, referral process, and method of transferring the injured patient and type or diagnosis of injuries.

This review found that the major cause of ambulance delay is traffic (5 studies, $71.4 \%$ ) as depicted in Figure 2.

\subsection{Factor of Ambulance Crash}

\subsubsection{Study Characteristic}

Five studies were assessed after full-text screening. All included studies were conducted in developed countries and discussed factors that caused ambulance crashes. All included studies applied cohort-study to identify factors that cause ambulance crashes ranging from within 2-10 years. A total sum of 5,031 ambulance crash cases were evaluated from five included articles.

\subsubsection{Outcome}

From the 5 studies that were reviewed, generally there were 6 factors that mostly influence on 
Table 1. Critical appraisal for cohort study

\begin{tabular}{|c|c|c|c|c|c|c|c|}
\hline & $\begin{array}{l}\text { Sanddal } \\
\text { et al., } \\
2010\end{array}$ & $\begin{array}{l}\text { Kahn et } \\
\text { al., } 2001\end{array}$ & $\begin{array}{l}\text { Ray et al., } \\
2005\end{array}$ & $\begin{array}{l}\text { Ray et al., } \\
2007\end{array}$ & $\begin{array}{l}\text { Custalow } \\
\text { et al., } \\
2004 \\
\end{array}$ & $\begin{array}{l}\text { David C et } \\
\text { al., } 2012\end{array}$ & $\begin{array}{l}\text { Lam et } \\
\text { al., } 2015\end{array}$ \\
\hline $\begin{array}{l}\text { Were the two groups similar } \\
\text { and recruited from the same } \\
\text { population? }\end{array}$ & 1 & 1 & 1 & 1 & 1 & 1 & 1 \\
\hline $\begin{array}{l}\text { Were the exposures measured } \\
\text { similarly to assign people to both } \\
\text { exposed and unexposed groups? }\end{array}$ & 1 & 1 & 1 & 1 & 1 & 1 & 1 \\
\hline $\begin{array}{l}\text { Was the exposure measured in a } \\
\text { valid and reliable way? }\end{array}$ & 1 & 1 & 1 & 1 & 1 & 1 & 1 \\
\hline $\begin{array}{l}\text { Were confounding factors } \\
\text { identified? }\end{array}$ & 0 & 1 & 0 & 0 & 0 & 1 & 1 \\
\hline $\begin{array}{l}\text { Were strategies to deal with } \\
\text { confounding factors stated? }\end{array}$ & 0 & 0 & 0 & 0 & 0 & 1 & 1 \\
\hline $\begin{array}{l}\text { Were the groups/participants } \\
\text { free of the outcome at the start } \\
\text { of the study (or at the moment of } \\
\text { exposure)? }\end{array}$ & 1 & 1 & 1 & 1 & 1 & 1 & 1 \\
\hline $\begin{array}{l}\text { Were the outcomes measured in a } \\
\text { valid and reliable way? }\end{array}$ & 1 & 1 & 1 & 1 & 1 & 1 & 1 \\
\hline $\begin{array}{l}\text { Was the follow up time reported } \\
\text { and sufficient to be long enough } \\
\text { for outcomes to occur? }\end{array}$ & 1 & 1 & 1 & 1 & 1 & 1 & 1 \\
\hline $\begin{array}{l}\text { Was follow up complete, and if not, } \\
\text { were the reasons to loss to follow } \\
\text { up described and explored? }\end{array}$ & 1 & 1 & 1 & 1 & 1 & 1 & 1 \\
\hline $\begin{array}{l}\text { Were strategies to address } \\
\text { incomplete follow up utilized? }\end{array}$ & 0 & 0 & 0 & 0 & 0 & 0 & 0 \\
\hline $\begin{array}{l}\text { Was appropriate statistical analysis } \\
\text { used? }\end{array}$ & 1 & 1 & 1 & 1 & 1 & 1 & 1 \\
\hline Total & 8 & 9 & 8 & 8 & 8 & 10 & 10 \\
\hline
\end{tabular}

Table 2. Critical appraisal for qualitative study

\begin{tabular}{|c|c|c|c|}
\hline & $\begin{array}{l}\text { Griffin et al., } \\
2012\end{array}$ & $\begin{array}{l}\text { Patel et al., } \\
2017\end{array}$ & $\begin{array}{l}\text { Noorani et al., } \\
2014\end{array}$ \\
\hline $\begin{array}{l}\text { Is there congruity between the stated philosophical perspective and the } \\
\text { research methodology? }\end{array}$ & 1 & 1 & 1 \\
\hline $\begin{array}{l}\text { Is there congruity between the research methodology and the research } \\
\text { question or objectives? }\end{array}$ & 1 & 1 & 1 \\
\hline $\begin{array}{l}\text { Is there congruity between the research methodology and the methods } \\
\text { used to collect data? }\end{array}$ & 1 & 1 & 1 \\
\hline $\begin{array}{l}\text { Is there congruity between the research methodology and the } \\
\text { representation and analysis of data? }\end{array}$ & 1 & 1 & 1 \\
\hline $\begin{array}{l}\text { Is there congruity between the research methodology and the } \\
\text { interpretation of results? }\end{array}$ & 1 & 1 & 1 \\
\hline Is there a statement locating the researcher culturally or theoretically? & 0 & 1 & 0 \\
\hline $\begin{array}{l}\text { Is the influence of the researcher on the research, and vice- versa, } \\
\text { addressed? }\end{array}$ & 0 & 0 & 0 \\
\hline Are participants, and their voices, adequately represented? & 1 & 1 & 1 \\
\hline $\begin{array}{l}\text { Is the research ethical according to current criteria or, for recent } \\
\text { studies, and is there evidence of ethical approval by an appropriate } \\
\text { body? }\end{array}$ & 1 & 1 & 1 \\
\hline $\begin{array}{l}\text { Do the conclusions drawn in the research report flow from the analysis, } \\
\text { or interpretation, of the data? }\end{array}$ & 1 & 1 & 1 \\
\hline Total & 8 & 9 & 8 \\
\hline
\end{tabular}


Table 3. Critical appraisal for cross sectional study

\begin{tabular}{lll}
\hline & Saleh et al., 2018 & Dimitriou et al., 2018 \\
\hline Were the criteria for inclusion in the sample clearly defined? & 1 & 1 \\
\hline Were the study subjects and the setting described in detail? & 1 & 1 \\
\hline Was the exposure measured in a valid and reliable way? & 1 & 1 \\
\hline Were objective, standard criteria used for measurement of the condition? & 1 & 1 \\
\hline Were confounding factors identified? & 0 & 1 \\
\hline Were strategies to deal with confounding factors stated? & 0 & 1 \\
\hline Were the outcomes measured in a valid and reliable way? & 1 & 1 \\
\hline Was appropriate statistical analysis used? & 1 & 1 \\
\hline Total & 6 & 8 \\
\hline
\end{tabular}
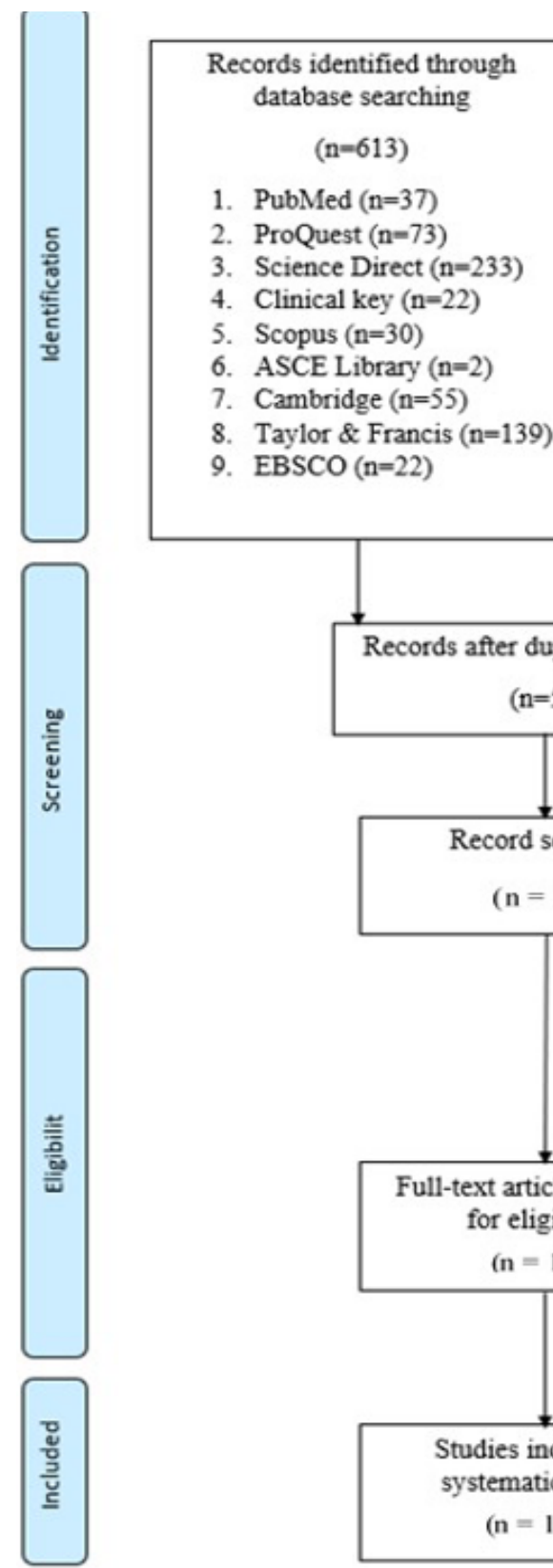

1. Manual search $(\mathrm{n}=6)$

2. Bibliography from other study $(\mathrm{n}-1)$

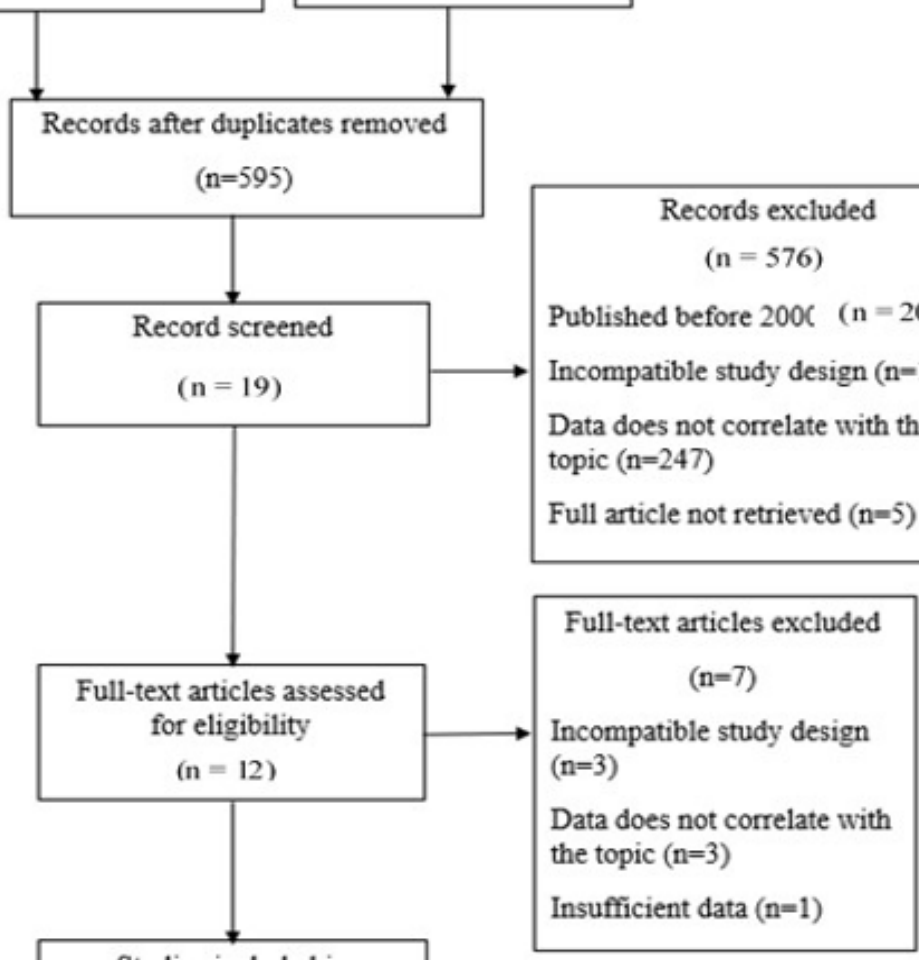

Studies included in systematic review $(\mathrm{n}=12)$

Figure 1. Literature search, selection, and inclusion flowchart 
ambulance crashes: intersection, turns, other vehicle carelessness, ambulance operator carelessness, road conditions, and traffic regulation violations. In a study conducted by Kahn, Kuhn, and Pirallo, ${ }^{16}$ the most influential factors in ambulance crashes are intersections, turns and other driver carelessness. Meanwhile, a study conducted by Custalow and Gravitz, ${ }^{17}$ said that violations of traffic lights, intersections, and other drivers' carelessness due to alcohol are the main factors of ambulance crashes. Intersection, turns, and collisions at traffic lights are also a major factor in ambulance crashes in studies conducted by Ray and Kupas. ${ }^{18}$ Ray and Kupas ${ }^{19}$ also conducted a study which stated that accidents in urban areas were mostly caused by turns, intersections, and carelessness from ambulance operators, while in rural areas many were caused by road conditions. Moreover, intersection, road condition, and ambulance operator carelessness are the main causes of accidents in a study conducted by Sanddal, Sanddal, Ward, and Satanley. ${ }^{20}$ Figure 3 below illustrates factors causing ambulance crash which is dominated by intersection crashes (5 studies, 100\%).

\section{Discussion}

\subsection{Factor of Ambulance Delay}

Two of the three studies that calculated the delay time interval showed the highest delay time in traffic jams. The study conducted by Griffin ${ }^{13}$ showed that the average traffic jam caused an ambulance delay of 10 minutes and a study conducted by Lam ${ }^{12}$ gave the result that a dense traffic condition caused an ambulance delay of 12.98 minutes longer than rare traffic conditions. Two studies using qualitative methods showed that almost all respondents agreed that traffic conditions were the main contributor to ambulance delays. The respondents also gave the main problem of traffic conditions in the form of vehicle density, poor knowledge of traffic rules, and distance. Two studies that counted the number of ambulance delay cases also showed that traffic congestion was a major influence on traffic conditions. Hence, from the literature we find that traffic conditions are the main cause of ambulance delay.

\subsection{Factor of Ambulance Crash}

Based on the journals obtained, the intersection was the main cause of the ambulance crash. Ambulance routes with multiple intersections increase the risk of ambulance accidents. Intersections are considered a dangerous site for ambulances and intersections have been used several times as intervention point by police agencies..$^{16}$ Intersections are also the place where ambulance crashes cause the most trauma to ambulance passengers. Ambulance drivers are required to pass the intersection with high vigilance by slowing down the speed of the vehicle to ensure that traffic is safe to pass and making eye contact with other drivers before crossing the intersection. ${ }^{17}$ Ambulance crashes often occur at four-way intersections. An increase in the incidence of ambulance collisions at intersections was recorded in those with traffic signals. ${ }^{18}$ Ambulance crashes that occur at the intersection often occur in urban areas. ${ }^{19}$ From the facts obtained from the literature, the results support that intersections are the main factor of ambulance crashes.

Ambulance crashes cause a slowing of patient delivery and have the potential to worsen and endanger the condition of patients, ambulance officers, and other drivers. ${ }^{21}$ The existence of an ambulance crash will cause additional victims who need to be treated and will aggravate the patient's condition compared to before the ambulance crash occurred. This will require additional medical personnel both to bring them to health facilities and to handle them.

\subsection{The Correlation Between the Factors of Ambulance Delay and Ambulance Crash}

Ambulance response time and ambulance safety to deliver patients in order to get treatment as soon as possible is one of the key indicators of trauma management. ${ }^{12}$ Increasing the number of vehicles has an impact on increasing traffic density. The rapid growth in the number of vehicles in developing countries further increases the risk of ambulance delays and ambulance crashes either to pick up or deliver patients to the nearest health facility. ${ }^{4}$

Based on results of this study, the most important factor causing ambulance delays is traffic congestion 


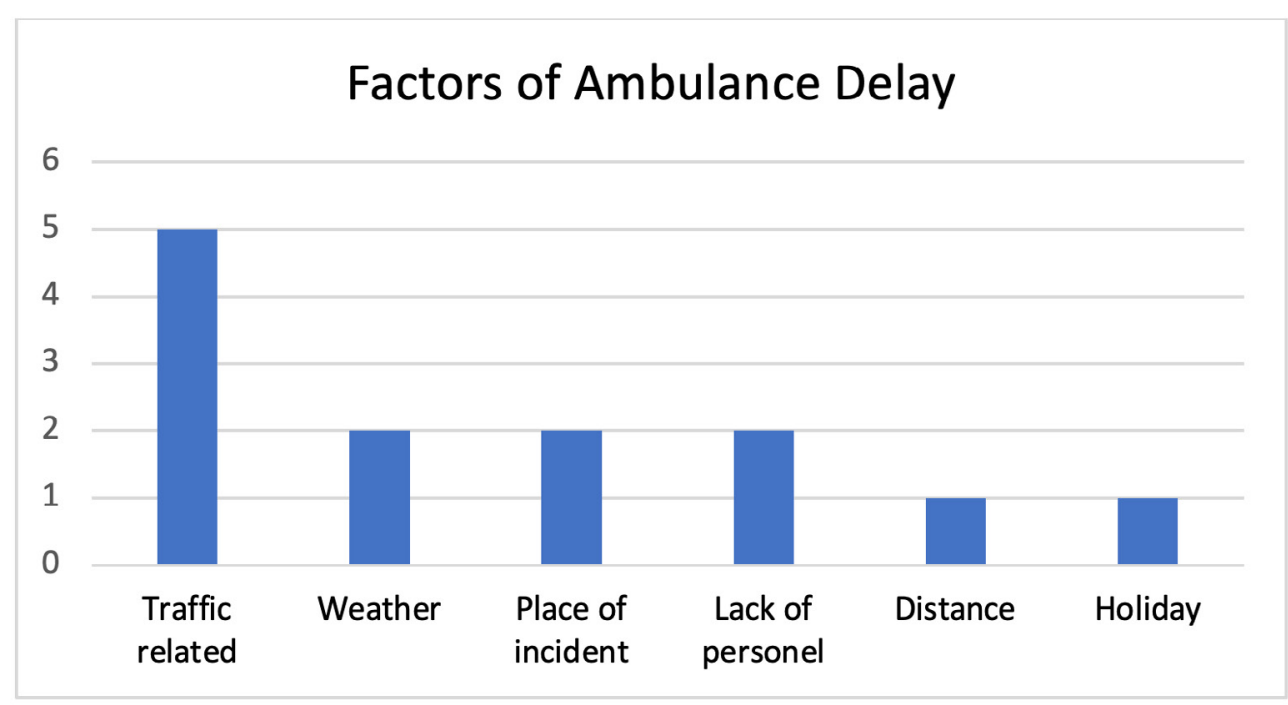

Figure 2. Graphic of factor ambulance delay

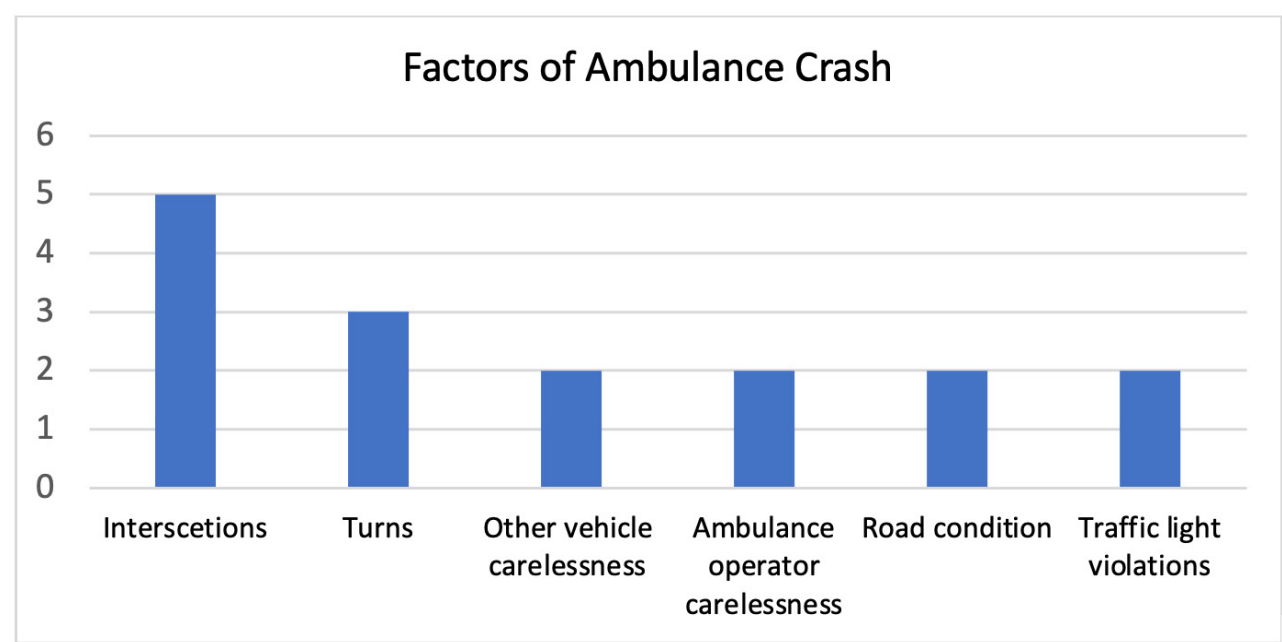

Figure 3. Graphic of factor ambulance crash

and the most important factor causing ambulance crashes is intersections. Factors that cause ambulance delay and factors that cause ambulance crash actually are interconnected. Traffic congestion often occurs especially due to the traffic signal at intersections. ${ }^{12}$ This traffic congestion causes the ambulance to not be able to pass due to the congested road traffic even though the ambulance sounds its emergency siren. ${ }^{17}$ Accordingly, intersections have significant effect on ambulance delays and also ambulance crashes. This finding highlights the need to conduct more in-depth research about solutions to reduce ambulance delays and ambulance crashes. ${ }^{16}$

\subsection{Comparison to Related Studies}

There were two literature reviews collected about the factors that cause ambulance crashes and one systemic review about the factors that cause ambulance accidents. The literature review by Hongwei and his friends, ${ }^{22}$ reviewed a wide field of literature related to the factors that cause emergency vehicle accidents, and reported risk factors, control measures, and knowledge gaps relevant to emergency vehicle accidents. Emergency vehicles are at risk between emergency response and returning from a call, due to disruption in driving emergency vehicles, driver assistance technology in 
vehicles, and vehicle red lights running on and off.

The literature review by Sanddal and his friends ${ }^{23}$ stated that ambulance crashes occur with greater frequency and severity than crashes involving vehicles of similar size and weight characteristics. Crashes in rural areas tend to be more severe in terms of injury or death to vehicle occupants. An annotated bibliography is followed by a discussion and conclusion that identify opportunities for prevention activities in the areas of education, enforcement, and engineering.

The systemic review by Li and his friends ${ }^{24}$ found that many researchers have investigated areas of emergency department crowding and ambulance diversion; however, research focused solely on the ambulance offload delay problem is limited. A common theme found throughout the reviewed articles was that this problem includes clinical, operational, and administrative perspectives, and therefore must be addressed in a system-wide manner to be mitigated.

Furthermore, the authors found that there is no individual study that assessed both ambulance delay and ambulance crash factors. Likewise, there is no literature that connects the factor of ambulance delay with the factor of ambulance crash.

\section{Conclusion}

This review suggests that traffic conditions are the main factor causing ambulance delays, while the intersection is the main factor causing ambulance crashes. Traffic conditions and intersections have a close relationship, where most traffic congestion occurs at the intersection. Intersections cause a significant impact on ambulance crashes and ambulance delays. Therefore, there is a demand for a strategic solution to reduce the adverse effects of the intersection on ambulances. The authors suggest to modify the traffic pattern using additional ambulance caution signal lamps at congested intersection and examine the impact on the community. Further studies on the effectiveness of traffic modification and interventions to mitigate ambulance crashes and delays should be performed.

\section{Acknowledgments}

This study did not receive specific grants from funding agencies in the public sector, commercial, or non-profit sector. Despite some aspect of this study was presented in Pre-Conference Competition Asian Medical Students' Conference 2020, this manuscript has never been submitted to any publisher for publication.

\section{Conflict of interest}

The authors declare no competing interest related to this study.

\section{References}

1. World Health Organization. Injuries and violence: the facts [Internet]. 2015 [cited 2020 Mar 7]. Available from: https://www.who.int/ violence_injury_prevention/media/news/2015/ Injury_violence_facts_2014/en/

2. Center of Disease Control and Prevention. Ten Leading Causes of Death and Injury [Internet]. 2017 [cited 2020 Mar 7]. Available from: https:// www.cdc.gov/injury/wisqars/LeadingCauses. html

3. Abbasi H, Bolandparvaz S, Yadollahi M, Anvar $M$, Farahgol Z. Time distribution of injuryrelated in-hospital mortality in a trauma referral center in South of Iran (2010 - 2015). Medicine (Baltimore). 2017;1-6.

4. Patel A, Ricardo J, Vissoci N, Hocker M, Molina E, Gil NM, et al. Qualitative evaluation of trauma delays in road traffic injury patients in Maringá, Brazil. BMC Health Serv Res. 2017;17(1):804.

5. Kementrian Komunikasi dan Informatika Republik Indonesia. Rata-rata Tiga Orang Meninggal Setiap Jam Akibat Kecelakaan Jalan [Internet]. 2017 [cited 2020 May 28]. Available from: https://kominfo.go.id/index.php/content/ detail/10368/rata-rata-tiga-orang-meninggalsetiap-jam-akibat-kecelakaan-jalan/0/artikel_ gpr

6. The Nation. 20 Percent of Emergency Patient Deaths Blamed on Traffic Jam Delays [Internet]. 2017 [cited 2020 Mar 7]. Available from: https:// www.nationthailand.com/national/30304268 
7. Smith N. A national perspective on ambulance crashes and safety. EMSWORLD. 2015;91-04.

8. Carter N, Bryant-lukosius D, Dicenso A, Blythe J, Nevile AJ. The use of triangulation in qualitative research. Oncol Nurs Forum. 2014;41(5):545-7.

9. The Joanna Briggs Institute. Critical Appraisal Tools [Internet]. The Joanna Briggs Institute. [cited 2019 Feb 10]. Available from: https:// joannabriggs.org/ebp/critical_appraisal_tools

10. Noorani MM, Khaliq MF, Shoaib M, Sheikh A, Moughal $U$, Moazzum $W$, et al. Time intervals and associated factors of emergency treatment: first insight into Pakistani system. Int Arch Med. 2014;7(1):1-9.

11. Dimitriou L, Efthymiou D, Antoniou C. Saving lives through faster emergency unit response times: role of accessibility and environmental factors. J Transp Eng. 2018;144(9):1-9.

12. Lam SSW, Nguyen FNHL, Ng YY, Lee VP-X, Wong $\mathrm{TH}$, Fook-Chong SMC, et al. Factors affecting the ambulance response times of trauma incidents in Singapore. Accid Anal Prev. 2015;82:27-35.

13. Griffin R, McGwin Jr G. Emergency medical service providers' experiences with traffic congestion. J Emerg Med [Internet]. 2013;44(2):398-405. Available from: http://dx.doi.org/10.1016/j. jemermed.2012.01.066

14. XUE S, WENG J. Analysis of uncertainty associated with response time in work zone traffic accidents. CICTP. 2014;3710-22.

15. Saleh HM, Elsabagh $A E$, Elewa MG, Fawzy AA, Hassan OM, Comer AC, et al. Admission delays' magnitude of traumatized patients in the emergency department of a hospital in Egypt: a cross- sectional study. Eur J Trauma Emerg Surg. 2017;44(2):225-230.

16. Kahn CA, Pirrallo RG, Kuhn EM. Characteristics of fatal ambulance crashes in the United States: an 11-year retrospective analysis. Prehospital Emerg Care . 2001;5(3):261-9.

17. Custalow CB, Gravitz CS. Emergency medical vehicle collisions and potential for preventive intervention. Prehospital Emerg Care. 2004;8(2):175-84.

18. Ray AF, Kupas DF. Comparison of crashes involving ambulances with those of similar-sized vehicles. Prehospital Emerg Care. 2005;412-5.

19. Ray AM, Kupas DF. Comparison of rural and urban ambulance crashes in Pennsylvania. Prehospital Emerg Care. 2007;416-20.

20. Sanddal TL, Sanddal ND, Ward N, Stanley L. Ambulance crash characteristics in the US defined by the popular press: a retrospective analysis. Emerg Med Int. 2010;1-7.

21. Pattanarattanamolee $R$, Lertsinudom $S$, Nakahara S, Sakamoto T. Ambulance crash in a rural area of Thailand. Int Emerg Med [Internet]. 2017;53(5):1-5. Available from: https://doi. org/10.1016/j.jemermed.2017.08.017

22. Hsiao $H$, Virginia W. Preventing emergency vehicle crashes: status and challenges of human factors issues. Hum Factors J Hum Factors Ergon Soc. 2018;60(7):1048-72.

23. Sanddal N, Albert S, Hansen J, Kupas D. Contributing factors and issues associated with rural ambulance crashes: literature review and annotated bibliography. Prehospital Emerg Care. 2008;12(2):257-67.

24. Li M, Vanberkel P, Carter AJE. A review on ambulance offload delay literature. Health Care Manag Sci. 2018;22(4):658-75. 